\title{
Diagnostic Accuracy of Non-invasive Laboratory-Based Fibrosis Scores in Predicting the Presence of Esophageal Varices in Liver Cirrhosis
}

\author{
Rajesh Pandey*, Rahul Pathak, Arun Gnawali, Prem Krishna Khadga, Sashi Sharma, Anurag Jha, Rabin Hamal, Dinesh \\ Koirala, Pawan Parajuli
}

Department of Gastroenterology and Hepatology, Maharajgunj Medical Campus, TUTH, Institute of Medicine, Kathmandu, Nepal

Keywords: Cirrhosis, AAR, APRI, FIB-4, King Score, Lok scores, noninvasive predictors

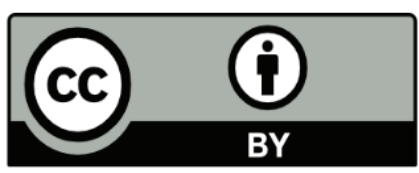

This work is licensed under a Creative Commons Attribution 4.0 Unported License.

\section{Introduction}

Cirrhosis is the end-stage for chronic liver disease and is the leading cause of liver-related death globally.' Cirrhosis is frequently compensated. The development of complications of portal hypertension and/or liver dysfunction is decompensated cirrhosis. It is defined by the presence of variceal hemorrhage, ascites, encephalopathy, hepatorenal syndrome, jaundice or hepatocellular carcinoma. The transition from a compensated to a decompensated stage occurs at a rate of 5 to $7 \%$ per year. $^{2}$ Esophageal variceal bleeding is a life-threatening portal hypertension-related complication in liver cirrhosis. ${ }^{3}$ Esophageal varices are present at diagnosis in approximately $50 \%$ of cirrhotic patients and the rate of development of new varices and increase in grades of varices is $8 \%$ per year. ${ }^{4}$ The mortality is $3.4 \%$ per year in patients with non-bleeding varices. By comparison, the mortality rises to $57 \%$ per year in patients with variceal bleeding. Thus, early diagnosis of varices and primary prophylaxis of variceal bleeding in high-risk patients with liver cirrhosis is important in improving survival. ${ }^{5}$

Esophagogastroduodenoscopy (EGD) is the gold standard for diagnosing varices in liver cirrhosis. However, because of its invasiveness and discomfort, most patients are reluctant to undergo this procedure. The progression of fibrosis parallels the increase in portal pressure, ${ }^{6}$ as liver fibrosis contributes to the

\section{Abstract}

Introduction: Non-invasive assessment of esophageal varices (EVs) may reduce endoscopic burden and cost. This study aimed to evaluate the diagnostic accuracy of non-invasive fibrosis scores (AAR, APRI, FIB-4, King and Lok scores) for the prediction of varices in liver cirrhosis.

Methods: This prospective study included 100 liver cirrhosis patients who underwent screening endoscopy for EVs. AAR, APRI, FIB-4, King and Lok scores were assessed. The receiver operating characteristic curves (ROC) were plotted to measure and compare the performance of each score for predicting EVs and to obtain the corresponding optimal prediction value.

Results: Of the 100 patients, 70 were males and 30 were females with a mean age of $54.05 \pm 11.58$ years. Esophageal varices were found in 77 patients out of which $58.44 \%$ were high-risk varices. Platelet count and non-invasive fibrosis scores APRI, FIB-4, Lok and King were able to discriminate patients with and without varices. Using area under receiver operating characteristic curve (AUROC), these scores were found to have low to moderate diagnostic accuracy for the presence of EVs and high-risk EVs, where the APRI score had the highest AUROC (0.77 and 0.70$)$ respectively. At a cutoff value $>1.4$, APRI score had $90.9 \%$ sensitivity, $60.9 \%$ specificity and $84 \%$ diagnostic accuracy in predicting the presence of varices, while it had $84.4 \%$ sensitivity, $45.5 \%$ specificity and $63 \%$ diagnostic accuracy in predicting the presence of highrisk varices, at a cutoff value $>2.02$.

Conclusion: APRI, AAR, FIB-4, King, and Lok scores had low to moderate diagnostic accuracy in predicting the presence of varices in liver cirrhosis. The APRI score can help select a patient for the endoscopy but cannot replace endoscopy for esophageal varices screening.

\section{*Corresponding Author:}

Dr. Rajesh Pandey, MBBS, MD

Department of Gastroenterology and Hepatology, Maharajgunj

Medical Campus, TUTH, Institute of Medicine, Kathmandu, Nepal Email: rajeshpandeya@gmail.com, Phone: +977-9849042943 
increased hepatic resistance. Several non-invasive markers of varices are primarily derived from the non-invasive assessment of liver fibrosis. They are more convenient and cheap in clinical practices. Aspartate Aminotransferase-platelet ratio index (APRI) and Fibrosis-4 (FIB-4) scores have good accuracy in predicting fibrosis.? 8 Several studies including meta-analysis have demonstrated that the diagnostic accuracy of APRI, Aspartate aminotransferase-Alanine aminotransferase ratio (AAR), FIB-4, Lok and King score was modest. ${ }^{7,9}$

In a country like Nepal, where availability and affordability of endoscopy service is still an issue, these non-invasive scores may reduce endoscopic burden, cost, and drawbacks. This study aims to evaluate the diagnostic accuracy of APRI, AAR, FIB-4, Lok scores and King scores in predicting the presence of varices and high-risk varices in liver cirrhosis.

\section{Methods:}

This prospective study was carried out at the Department of Gastroenterology, Tribhuvan University Teaching Hospital, Maharajgunj, Kathmandu, Nepal from August 2019 to February 2020. This study included 100 adult patients with liver cirrhosis presenting in the outpatient department of Gastroenterology, Tribhuvan University Teaching Hospital, who were selected using the non-probability consecutive sampling method. Cirrhotic patients had diagnostic criteria of liver cirrhosis by clinical (stigmatas of chronic liver disease), biochemical (impaired liver function test consistent with cirrhosis) and ultrasonographic findings (shrunken or enlarged nodular liver with increased echotexture, irregular margins and distorted architecture, with or without a dilated portal vein, thickened gallbladder wall, splenomegaly or ascites). ${ }^{10}$ Patients who were less than 18 years of age, were unable to provide informed consent, had active or previous variceal bleeding, had received prior variceal treatment (any type) or variceal bleeding prophylaxis (including nonselective $\beta$-blocker use), had pre-existing other comorbidities (hypertension grade 2 or 3, COPD patients requiring oxygen via face mask, chronic kidney disease and heart failure NYHA class III or IV) or were pregnant were excluded from the study.

130 cirrhotic patients screened

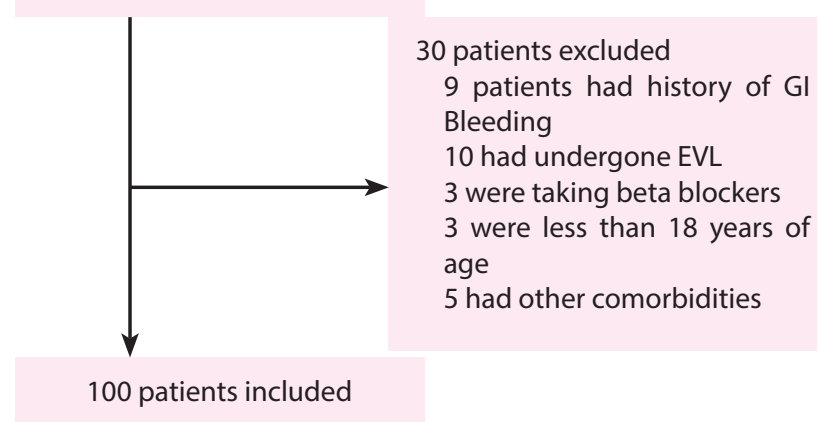

Fig 1: Study design

All patients included in the study were evaluated for clinical, hematological, biochemical and ultrasonographic parameters. Non-invasive fibrosis scores were calculated as follows:

AAR $=$ AST (IU/L)/ALT (IU/L). ${ }^{11}$

APRI $=($ AST $($ IU/L) $/$ AST (Upper Limit of Normal) $(I U / L)) /$ Platelets $\left(10^{9} / \mathrm{L}\right) \times 100 .^{12}$

FIB-4 $=\left[\right.$ Age $($ years $) \times$ AST $($ IU/L) $] /\left[\right.$ Platelets $\left(10^{9} / \mathrm{L}\right) \times$ ALT $\left.(I U / L)^{1 / 2}\right] .^{13}$
King score $=$ Age $($ years $) \times$ AST $(I U / L) \times I N R /$ Platelets $\left(10^{9} / \mathrm{L}\right) .{ }^{14}$

Lok Score $=-5.56-0.0089 \times$ Platelets $\left(10^{9} / \mathrm{L}\right)+1.26 \times$ AST $/$ ALT + $5.27 \times$ INR $^{9}$

All patients underwent EGD to evaluate for the presence and degree of esophageal varices using a Pentax Endoscope EG2990l. UGl endoscopies were carried out mostly by the single gastroenterologist during the study period. Esophageal varices were classified into small and large varices based on Baveno consensus..$^{15}$ The presence or absence of red color signs was also noted. High-risk varices included large varices and small varices with red color signs.

The study was approved by the Institutional Review Committee of the Institute of Medicine, TUTH. Written informed consent was obtained from all patients before enrollment.

All statistical analyses were conducted using Statistical Package for the Social Sciences (SPSS) for Windows version 23 (SPSS Inc., Chicago, IL, USA). Data were expressed as mean and standard deviation (SD), median and interquartile range, and proportions and 95\% Confidence Interval $(\mathrm{Cl})$ as appropriate. A p-value of $<0.05$ was considered statistically significant in all analyses. Continuous variables (such as laboratory data, fibrosis score) were compared using the Student t-test and the Mann-Whitney $U$ test, as appropriate.

To determine test performance for prediction of EVs, a receiver operator characteristic curve was constructed and the area under the ROC curve (AUROC) was calculated. The cutoff value of the variables was determined at the point of the highest sensitivity and specificity. Sensitivity, specificity, predictive values, and likelihood ratios were calculated for these cutoff values.

Results:

Out of 130 patients initially screened, 30 patients were excluded and a hundred patients with liver cirrhosis were included. Mean age was $54.05 \pm 11.58$ years. Among them, 70 were males and 30 were females. The most common age group involved was 41-65 years $(72 \%)$, followed by $>65$ years (15\%) and $16-40$ years (13\%). As shown in Fig. 2, Alcoholic liver disease was the most common cause of cirrhosis, followed by chronic hepatitis $B$ and chronic hepatitis $C$.

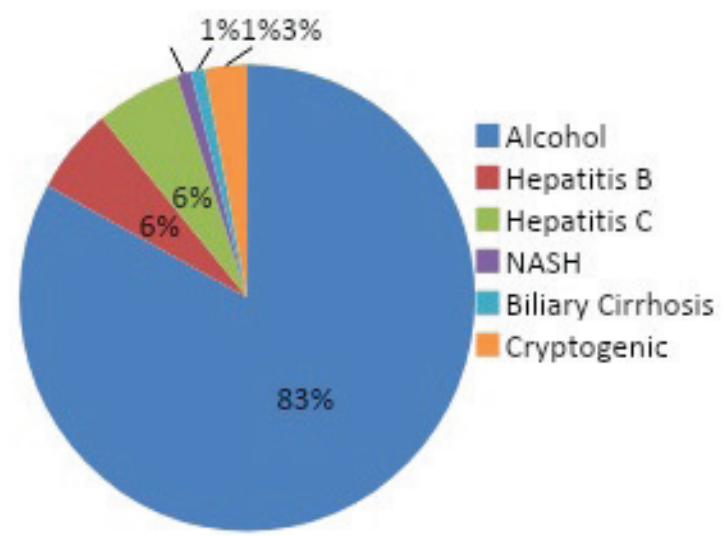

Fig. 2: Etiology of Cirrhosis of Liver

Majority of the patients belonged to Child-Turcotte Pugh Class C (62\%), followed by CTP Class B (28\%) and CTP Class A (10\%). Seventy-seven patients (77\%) had esophageal varices. Among 
them $32(41.55 \%)$ had small varices without red color signs, 15 (19.48\%) had small varices with red color signs and 30 (38.96\%) had large varices. Baseline demographic and clinical characteristics of the studied patients with and without varices are summarized in Table 1. Platelet count and non-invasive fibrosis scores APRI, FIB-4, Lok and King were able to discriminate patients with and without varices.

\begin{tabular}{|c|c|c|c|}
\hline Variables & Varices $(n=77)$ & $\begin{array}{l}\text { No varices } \\
\quad(n=23)\end{array}$ & p-value \\
\hline $\begin{array}{l}\text { Age (years, } \\
\text { Mean } \pm \text { SD) }\end{array}$ & $52.8 \pm 11.1$ & $58.1 \pm 12.4$ & 0.330 \\
\hline \multicolumn{4}{|c|}{ Laboratory parameters (Mean \pm SD) } \\
\hline $\begin{array}{l}\text { Platelets( } \\
\left.\times 10^{3} / \mu \mathrm{L}\right)\end{array}$ & $91.75 \pm 64.73$ & $184 \pm 96.22$ & 0.001 \\
\hline $\operatorname{ALT}(I U / L)$ & $51.31 \pm 31.51$ & $46.91 \pm 40.26$ & 0.195 \\
\hline $\begin{array}{c}\text { Total Bilirubin } \\
(\mu \mathrm{mol} / \mathrm{L})\end{array}$ & $145.37 \pm 143.82$ & $\begin{array}{l}81.26 \pm \\
121.45\end{array}$ & 0.078 \\
\hline INR & $2.21 \pm 1.44$ & $1.70 \pm 0.70$ & 0.155 \\
\hline $\begin{array}{l}\text { Creatinine } \\
(\mu \mathrm{mol} / \mathrm{L})\end{array}$ & $148.33 \pm 110.20$ & $\begin{array}{c}133.62 \pm \\
91.62\end{array}$ & 0.998 \\
\hline $\begin{array}{l}\text { Serum } \\
\text { Albumin } \\
\text { (gm/L) }\end{array}$ & $27.43 \pm 6.07$ & $29.44 \pm 10.55$ & 0.251 \\
\hline $\begin{array}{l}\text { Child-Pugh } \\
\text { score }\end{array}$ & $10.29 \pm 2.32$ & $9.17 \pm 2.91$ & 0.181 \\
\hline $\begin{array}{l}\text { MELD } \\
\text { Sodium }\end{array}$ & $25.58 \pm 9.13$ & $20.56 \pm 8.65$ & 0.495 \\
\hline MELD & $24.20 \pm 9.31$ & $19.34 \pm 8.79$ & 0.556 \\
\hline \multicolumn{4}{|c|}{ Fibrosis scores (median and interquartile range) } \\
\hline APRI & $2.96(1.75-4.96)$ & $\begin{array}{c}1.13(0.99- \\
2.08)\end{array}$ & 0.000 \\
\hline AAR & $1.92(1.40-3.17)$ & $\begin{array}{l}1.88(0.88- \\
3.15)\end{array}$ & 0.575 \\
\hline Lok Score & $1(0.98-1)$ & $0.99(0.81-1)$ & 0.049 \\
\hline FIB4 & $9.22(6.06-16.20)$ & $\begin{array}{c}4.68(2.38- \\
13.42)\end{array}$ & 0.007 \\
\hline King & $\begin{array}{c}119.00(54.96- \\
244.87)\end{array}$ & $\begin{array}{c}36.45(27.84- \\
87.23)\end{array}$ & 0.003 \\
\hline
\end{tabular}

MELD: Model for End Stage Liver Disease; Statistical analysis by student $t$ test and the Mann-Whitney $\mathrm{U}$ test

By measuring AUROC score, the diagnostic accuracies of AAR, APRI, FIB-4, King and Lok scores as non-invasive predictors of EVs were studied to determine the score that would have the most clinical utility for prediction (Fig. 2). For predicting EVs, the APRI score had the greatest AUROC of $0.77(95 \% \mathrm{Cl} 0.64-0.91)$, followed by King $[0.70(95 \% \mathrm{Cl} 0.56-0.85)]$, FIB-4 [0.69 (95\% Cl 0.54-0.83)], Lok scores [0.62 (95\% Cl 0.48-0.77)] and AAR [0.54 (95\% Cl 0.390.69)].

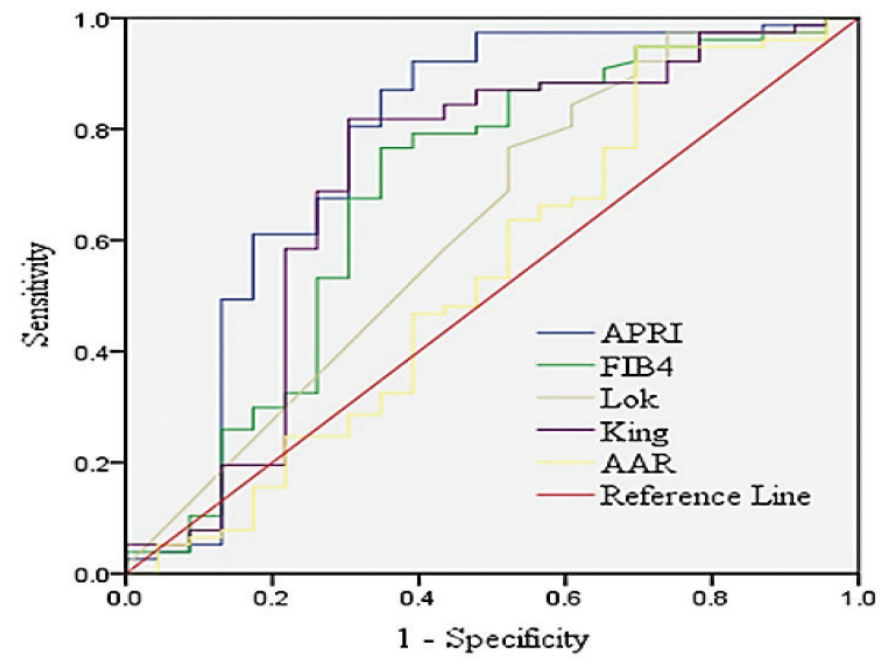

Fig. 2: Receiver operating characteristic curve of fibrosis scores to predict EVs

For predicting high-risk varices (Fig. 3), the APRI score had the greatest AUROC [0.70 (95\% CI 0.60-0.81)], followed by King score [0.67 (95\% Cl 0.57-0.78) ], FIB-4 score [0.64 (95\% Cl 0.53-0.75)], Lok Score $[0.60(95 \% \mathrm{Cl} 0.48-0.70)]$ and AAR [0.47(95\% Cl 0.36-0.80)].

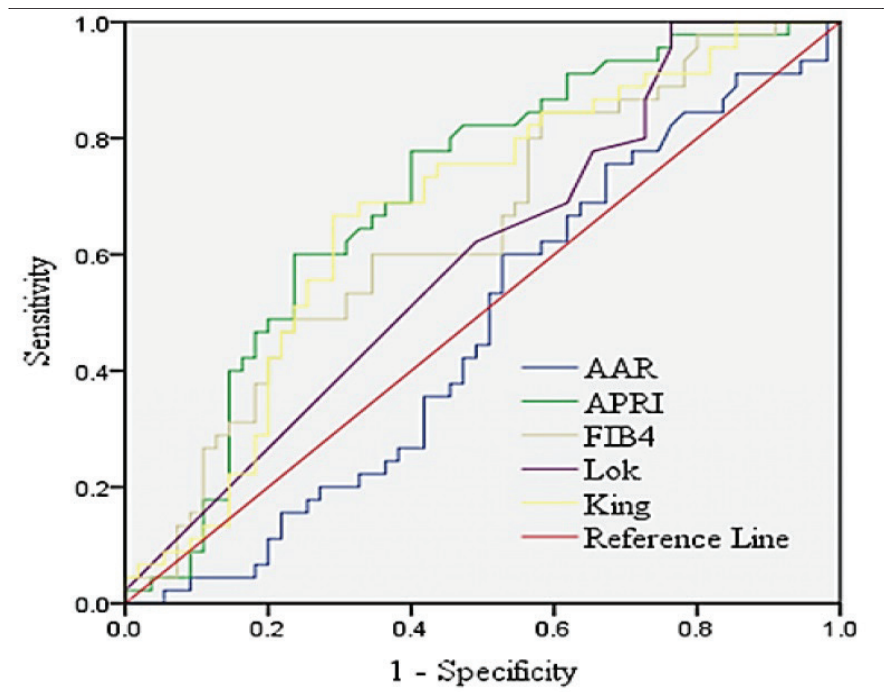

Fig 3: Receiver operating characteristic curve of fibrosis scores to predict high-risk EVs

The optimal cutoff values of the above-mentioned scores to predict the presence of esophageal varices is shown in Table 2. The APRI score had the highest diagnostic indices. At a cutoff value $>$ 1.4, APRI had $90.9 \%$ sensitivity,60.9 \% specificity, 88.6\% PPV, 66.7 $\%$ NPV and $84 \%$ accuracy for the prediction of EVs. 
Table 2: Diagnostic performance of fibrosis scores for prediction of EVs

\begin{tabular}{|c|c|c|c|c|c|c|}
\hline & $\begin{array}{l}\text { Cutoff } \\
\text { value }\end{array}$ & $\begin{array}{c}\text { Sensitivity } \\
(\%)\end{array}$ & $\begin{array}{c}\text { Specificity } \\
(\%)\end{array}$ & \begin{tabular}{|l} 
Positive \\
Predictive \\
Value (\%)
\end{tabular} & $\begin{array}{l}\text { Negative } \\
\text { Predictive } \\
\text { Value (\%) }\end{array}$ & $\begin{array}{c}\text { Accuracy } \\
(\%)\end{array}$ \\
\hline APRI & 1.4 & 90.9 & 60.9 & 88.6 & 66.7 & 84 \\
\hline AAR & 1.7 & 61 & 47.8 & 79.7 & 47.8 & 58 \\
\hline $\begin{array}{l}\text { Lok } \\
\text { Score }\end{array}$ & 0.97 & 76.6 & 47.8 & 83.1 & 37.9 & 70 \\
\hline FIB-4 & 6.4 & 74 & 65.2 & 87.7 & 42.9 & 72 \\
\hline $\begin{array}{l}\text { King } \\
\text { Score }\end{array}$ & 46.5 & 81.8 & 69.6 & 90 & 53.3 & 79 \\
\hline
\end{tabular}

Table 3 shows the optimal cutoff values of the above-mentioned scores to predict the presence of high-risk esophageal varices. The APRI score had the highest diagnostic indices. At a cutoff value $>2.02$, APRI had $84.4 \%$ sensitivity, $45.5 \%$ specificity, $55.9 \%$ PPV, $78.1 \%$ NPV and $63 \%$ accuracy for the prediction of high-risk varices.

Table 3: Diagnostic performance of fibrosis scores for prediction of high-risk EVs

\begin{tabular}{|c|c|c|c|c|c|c|}
\hline & $\begin{array}{c}\text { Cutoff } \\
\text { value }\end{array}$ & $\begin{array}{c}\text { Sensitivity } \\
(\%)\end{array}$ & $\begin{array}{c}\text { Specificity } \\
(\%)\end{array}$ & $\begin{array}{c}\text { Positive } \\
\text { Predictive } \\
\text { Value (\%) }\end{array}$ & $\begin{array}{c}\text { Negative } \\
\text { Predictive } \\
\text { Value (\%) }\end{array}$ & $\begin{array}{c}\text { Accuracy } \\
(\%)\end{array}$ \\
\hline APRI & 2.02 & 84.4 & 45.5 & 55.9 & 78.1 & 63 \\
\hline AAR & 1.89 & 51.1 & 49.1 & 45.1 & 55.1 & 50 \\
\hline $\begin{array}{c}\text { Lok } \\
\text { Score }\end{array}$ & 0.99 & 62.2 & 50.9 & 50.9 & 62.2 & 56 \\
\hline FIB-4 & 8.92 & 60 & 65.5 & 58.7 & 66.7 & 63 \\
\hline $\begin{array}{l}\text { King } \\
\text { Score }\end{array}$ & 93.28 & 68.9 & 67.3 & 63.3 & 72.5 & 68 \\
\hline
\end{tabular}

\section{Discussion:}

Screening EGD for varices is important in the management of cirrhosis. However, EGD is an invasive procedure and is not readily accepted by patients. Therefore, there is an increasing interest in developing non-invasive methods for the prediction of EVs. As the development of portal hypertension is due to the progression of hepatic fibrosis, non-invasive fibrosis scores have been used to predict the presence of oesophageal varices in patients with cirrhosis. ${ }^{2}$ In this study, the diagnostic accuracy of non-invasive fibrosis scores in predicting the presence of EVs and high-risk EVs was evaluated.

In this study, platelet count, APRI, FIB-4, Lok and King score were significantly able to discriminate patients with and without varices $(p<0.5)$. Adami et al. ${ }^{16}$ also showed similar finding with platelet and APRI score.

APRI had the best performance in the prediction of EVs (AUROC $=0.77)$ and high-risk EVs $(A \cup R O C=0.70)$. This finding is similar to those reported by Hassan et al., ${ }^{17}$ Morishita et al. ${ }^{18}$ and Zhang et al. ${ }^{19}$. In this study, a cutoff value of $>1.4$ was established for the presence of varices, at which sensitivity was $90.9 \%$, specificity was $60.9 \%$ and the overall diagnostic accuracy was $84 \%$. Likewise, a cutoff of $>2.02$ was established for the presence of high-risk varices, at which sensitivity was $84.4 \%$, specificity was $45.5 \%$ and the overall diagnostic accuracy was $63 \%$. In a study done by Pathak et al. ${ }^{20}$ using APRI cutoff of $>1.3$, sensitivity and specificity were 75 and $64.35 \%$ for the diagnosis of EVs. However, Deng, et al., 7 proposed that at a cutoff value of $>0.87$, the AUROC was 0.54 for the diagnosis of any grade EVs with $68 \%$ sensitivity, $46.2 \%$ specificity, while at a cutoff value of $>0.85$, the AUROC for predicting Large EVs was $0.51,68.8 \%$ sensitivity, and $41.3 \%$ specificity.

King Score had an AUROC of 0.70 and 0.67 for the prediction of EVs and high-risk EVs respectively. The cutoff values $>46.5$ and $>$ 93.28 were identified for diagnosis of EVs and high-risk EVs with $81.8,68.9 \%$ sensitivity and $69.6,67.3 \%$ specificity respectively. Hassan et al. ${ }^{17}$ showed a cutoff value of 24.7 , had an AUROC of $0.80,80 \%$ sensitivity and $76.5 \%$ specificity, for the diagnosis of EVs. While for a cut-off value of 39.01 , the AUROC was 0.78 , sensitivity was $69.6 \%$ and specificity was $87.1 \%$, for the prediction of varices needing treatment. However in the retrospective study by Deng et al., ${ }^{7}$ the best cutoff value for the diagnosis of EVs was 17.93, with an AUROC of $0.64,85.3 \%$ sensitivity and $44 \%$ specificity and the best cut-off value was 24.80 for diagnosis of high-risk EVs, with an AUROC of $0.65,97 \%$ sensitivity, and $53.6 \%$ specificity.

The AUROC for prediction of the presence of varices and high risk varices for FIB-4 were 0.69 and 0.64 respectively and the cutoff values $>6.4$ and $>8.92$ were identified for diagnosis of EVs and high-risk EVs with 74, 60\% sensitivity and 65.2, $65.5 \%$ specificity respectively. This finding was similar to the study done by Sebastiani et al. ${ }^{21}$ which showed similar AUROC of 0.64 and 0.63 but with different cutoff values of 3.5 and 4.3 for the prediction of EVs and large EVs respectively. However, FIB-4 showed better performance in the study done by Hassan et al. ${ }^{17}$ where the cutoff values $>2.8$ and 3.4 were used for which AUROCs were 0.80 and 0.81 for diagnosis of EVs and large EVs with 73.3, $78.3 \%$ sensitivity and $82.4,74.2 \%$ specificity respectively.

The Lok score was proposed during the Halt-C trial. ${ }^{22}$ The AUROC for prediction of the presence of varices and high risk varices for Lok score were 0.62 and 0.60 respectively and the cutoff values $>0.97$ and $>0.99$ were identified for diagnosis of EVs and high-risk EVs with 76.6, 62.2\% sensitivity and 47.8, $50.9 \%$ specificity respectively. Castéra et al. ${ }^{23}$ had demonstrated the AUROCs of 0.81 and 0.87 for the presence of EVs and large EVs respectively. Stefanescu et al. ${ }^{24}$ showed an acceptable AUROC of 0.69 and 0.73 for the presence of EVs and large EVs for the Lok score. In a large cohort, ${ }^{21}$ for a cutoff value of 0.9 , the Lok Score had an AUROC of 0.77 for the diagnosis of EV, while for a cutoff value of 1.5 the AUROC was 0.69 for the prediction of large EVs.

In this study, AAR had the lowest performance in the prediction of EVs (AUROC $=0.54$ ) and high-risk EVs (AUROC $=0.47$ ). The poor diagnostic accuracy of AAR in this study is similar to the findings of the study by Deng et al., 7 wich showed poor AUROCs of AAR for EVs (0.59) and large EVs (0.60). However, Castéra et al. ${ }^{23}$ showed AUROCs of AAR for EVs (0.83) and large EVs (0.79). Hassan et al. ${ }^{17}$ showed AUROCs of AAR for EVs (0.73) and large EVs (0.68) which is similar to the findings by Calvaruso et al. ${ }^{25}$

Cutoff values of non-invasive fibrosis scores for prediction of EVs and high-risk EVs score and AUROC comparing them with other investigators is summarised in Table 4. 


\begin{tabular}{|c|c|c|c|c|c|}
\hline \multicolumn{6}{|c|}{$\begin{array}{c}\text { Table 4: Cutoff values of non-invasive fibrosis scores for } \\
\text { prediction of EVs and high-risk EVs } \\
\text { score and AUROC comparing them with other investigators }\end{array}$} \\
\hline & Investigators & $\begin{array}{l}\text { Cutoff value } \\
\text { for prediction } \\
\text { of EVs }\end{array}$ & AUROC & \begin{tabular}{|c|} 
Cutoff \\
value for \\
prediction \\
of high \\
risk EVs
\end{tabular} & AUROC \\
\hline APRI & $\begin{array}{c}\text { Our study } \\
\text { Deng et al. }{ }^{7} \\
\text { Hassan et al. }{ }^{17} \\
\text { Morishita et al. }{ }^{18} \\
\text { Zhang et al. }^{19}\end{array}$ & $\begin{array}{l}>1.4 \\
>0.87 \\
>0.85 \\
>1.50 \\
>1.29\end{array}$ & $\begin{array}{l}0.77 \\
0.54 \\
0.79 \\
0.68 \\
0.68\end{array}$ & $\begin{array}{l}>2.02 \\
>0.85 \\
>1.22 \\
>1.62 \\
>1.4\end{array}$ & $\begin{array}{l}0.70 \\
0.51 \\
0.79 \\
0.67 \\
0.73\end{array}$ \\
\hline AAR & $\begin{array}{l}\text { Our study } \\
\text { Calvaruso et al. }{ }^{25} \\
\text { Castéra et al. }^{23} \\
\text { Deng et al. }{ }^{7} \\
\text { Hassan et al. }{ }^{17}\end{array}$ & $\begin{array}{l}>1.7 \\
>0.80 \\
\geq 1 \\
>1.25 \\
>0.67\end{array}$ & $\begin{array}{l}0.54 \\
0.73 \\
0.83 \\
0.59 \\
0.73\end{array}$ & $\begin{array}{l}>1.89 \\
>1 \\
\geq 1 \\
>1.25 \\
>0.74\end{array}$ & $\begin{array}{l}0.47 \\
0.75 \\
0.79 \\
0.60 \\
0.68\end{array}$ \\
\hline $\begin{array}{c}\text { Lok } \\
\text { Score }\end{array}$ & 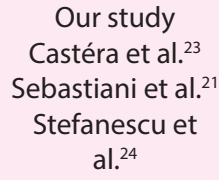 & $\begin{array}{l}>0.97 \\
\geq 0.6 \\
>0.9 \\
>0.62\end{array}$ & $\begin{array}{l}0.62 \\
0.81 \\
0.77 \\
0.69\end{array}$ & $\begin{array}{l}>0.99 \\
\geq 0.6 \\
>1.5 \\
>0.79\end{array}$ & $\begin{array}{l}0.60 \\
0.87 \\
0.69 \\
0.73\end{array}$ \\
\hline FIB-4 & $\begin{array}{l}\text { Our study } \\
\text { Hassan et al. }{ }^{17} \\
\text { Sebastiani et al. }{ }^{21}\end{array}$ & $\begin{array}{l}>6.4 \\
>2.8 \\
>3.5\end{array}$ & $\begin{array}{l}0.69 \\
0.80 \\
0.64\end{array}$ & $\begin{array}{l}>8.92 \\
>3.4 \\
>4.3\end{array}$ & $\begin{array}{l}0.64 \\
0.81 \\
0.63\end{array}$ \\
\hline $\begin{array}{l}\text { King } \\
\text { Score }\end{array}$ & $\begin{array}{l}\text { Our study } \\
\text { Deng et al. }{ }^{7} \\
\text { Hassan et al. }^{17}\end{array}$ & $\begin{array}{l}>46.5 \\
>17.93 \\
>24.7\end{array}$ & $\begin{array}{l}0.70 \\
0.64 \\
0.80\end{array}$ & $\begin{array}{l}>93.28 \\
>24.80 \\
>39.01\end{array}$ & $\begin{array}{l}0.67 \\
0.65 \\
0.78\end{array}$ \\
\hline
\end{tabular}

\section{Conclusion:}

In conclusion, the APRI score showed moderate diagnostic accuracy in predicting the presence of varices and high-risk varices. Whereas, other studied scores had low diagnostic accuracy. The APRI score can help select a patient for endoscopy. However, the studied non-invasive fibrosis scores might not be adequate to replace the use of EGD.

\section{Conflict of interest:}

None declared

\section{References}

1. Global, regional, and national age-sex-specific mortality for 282 causes of death in 195 countries and territories, 19802017: a systematic analysis for the Global Burden of Disease Study 2017. Lancet 2018;392(10159):1736-88.

2. D'Amico G, Garcia-Tsao G, Pagliaro L. Natural history and prognostic indicators of survival in cirrhosis: a systematic review of 118 studies. J Hepatol 2006;44(1):217-31.

3. Biecker E. Portal hypertension and gastrointestinal bleeding: diagnosis, prevention and management. World J Gastroenterol 2013;19(31):5035-50.
4. Groszmann RJ, Garcia-Tsao G, Bosch J, et al. Beta-blockers to prevent gastroesophageal varices in patients with cirrhosis. N Engl J Med 2005;353(21):2254-61.

5. de Franchis R. Revising consensus in portal hypertension: report of the Baveno V consensus workshop on methodology of diagnosis and therapy in portal hypertension. J Hepatol 2010;53(4):762-8.

6. Kumar M, Kumar A, Hissar S, et al. Hepatic venous pressure gradient as a predictor of fibrosis in chronic liver disease because of hepatitis B virus. Liver Int 2008;28(5):690-8.

7. Deng $\mathrm{H}$, Qi X, Peng $\mathrm{Y}$, et al. Diagnostic Accuracy of APRI, AAR, FIB-4, Fl, and King Scores for Diagnosis of Esophageal Varices in Liver Cirrhosis: A Retrospective Study. Med Sci Monit 2015;21:3961-77.

8. Pissaia A, Jr., Borderie D, Bernard D, et al. APRI and FIB-4 Scores Are Useful After Liver Transplantation Independently of Etiology. Transplant Proc 2009;41(2):679-81.

9. Deng H, Qi X, Guo X. Diagnostic Accuracy of APRI, AAR, FIB4, Fl, King, Lok, Forns, and Fibrolndex Scores in Predicting the Presence of Esophageal Varices in Liver Cirrhosis: A Systematic Review and Meta-Analysis. Medicine (Baltimore) 2015;94(42):e1795.

10. Heidelbaugh JJ, Bruderly M. Cirrhosis and chronic liver failure: part I. Diagnosis and evaluation. Am Fam Physician 2006;74(5):756-62.

11. Sheth SG, Flamm SL, Gordon FD, Chopra S. AST/ALT ratio predicts cirrhosis in patients with chronic hepatitis $C$ virus infection. Am J Gastroenterol 1998;93(1):44-8.

12. Wai C-T, Greenson JK, Fontana RJ, et al. A simple noninvasive index can predict both significant fibrosis and cirrhosis in patients with chronic hepatitis C. Hepatology 2003;38(2):51826.

13. Vallet-Pichard A, Mallet V, Nalpas B, et al. FIB-4: an inexpensive and accurate marker of fibrosis in HCV infection. comparison with liver biopsy and fibrotest. Hepatology 2007;46(1):32-6.

14. Cross TJS, Rizzi P, Berry PA, et al. King's Score: an accurate marker of cirrhosis in chronic hepatitis C. European Journal of Gastroenterology \& Hepatology 2009;21(7):730-38.

15. de Franchis R. Expanding consensus in portal hypertension: Report of the Baveno VI Consensus Workshop: Stratifying risk and individualizing care for portal hypertension. J Hepatol 2015;63(3):743-52.

16. Adami MR, Ferreira CT, Kieling CO, Hirakata V, Vieira SMG. Noninvasive methods for prediction of esophageal varices in pediatric patients with portal hypertension. World journal of gastroenterology 2013;19(13):2053-59.

17. Hassan E, El-Din S, Sharaf A, et al. Noninvasive Fibrosis Scores as Prognostic Markers for Varices Needing Treatment in Advanced Compensated Liver Cirrhosis. Open Journal of Gastroenterology 2017;7:230-42.

18. Morishita N, Hiramatsu N, Oze T, et al. Liver stiffness measurement by acoustic radiation force impulse is useful in predicting the presence of esophageal varices or highrisk esophageal varices among patients with HCV-related cirrhosis. J Gastroenterol 2014;49(7):1175-82.

19. Zhang F, Liu T. Predictive Value of a Noninvasive Serological 
Hepatic Fibrosis Scoring System in Cirrhosis Combined with Oesophageal Varices. Can J Gastroenterol Hepatol. 2018;2018:7671508.

20. Pathak R JR, Khadga P, Sharma S. Non-Endoscopic Parameters for Predicton of Esophageal Varices. JAIM 2017;6(2):21-26.

21. Sebastiani G, Tempesta D, Fattovich G, et al. Prediction of oesophageal varices in hepatic cirrhosis by simple serum non-invasive markers: Results of a multicenter, large-scale study. Journal of Hepatology 2010;53(4):630-38.

22. Lok AS, Ghany MG, Goodman ZD, et al. Predicting cirrhosis in patients with hepatitis $C$ based on standard laboratory tests: results of the HALT-C cohort. Hepatology 2005;42(2):282-92.

23. Castéra L, Bail BL, Roudot-Thoraval F, et al. Early detection in routine clinical practice of cirrhosis and oesophageal varices in chronic hepatitis C: Comparison of transient elastography (FibroScan) with standard laboratory tests and non-invasive scores. Journal of Hepatology 2009;50(1):59-68.

24. Stefanescu $H$, Grigorescu $M$, Lupsor $M$, et al. A new and simple algorithm for the noninvasive assessment of esophageal varices in cirrhotic patients using serum fibrosis markers and transient elastography. J Gastrointestin Liver Dis 2011;20(1):57-64.

25. Calvaruso V, Bronte F, Conte E, et al. Modified spleen stiffness measurement by transient elastography is associated with presence of large oesophageal varices in patients with compensated hepatitis $C$ virus cirrhosis. J Viral Hepat 2013;20(12):867-74. 